\title{
Sero-Prevalence and Risk Factors Associated With Foot and MouthDisease in Bauchi Local Government Area, Bauchi State Nigeria.
}

\author{
M.B Abubakar' A.U Abdulkadir' A.D. El-yuguda' T.M. Hamisu' S.S. Baba \\ Animal Virus Research Laboratory, Department of Veterinary Microbiology, Faculty of Veterinary Medicine, \\ University of Maiduguri, Maiduguri Nigeria.
}

\begin{abstract}
Foot and Mouth Disease (FMD) is a highly contagious viral transboundary disease of both domestic and wild cloven hoofed animals. It has low mortality rate in adult but with morbidity rate of up to $100 \%$ in susceptible animal populations. This research work was designed to determine the seroprevalence of FMD and risk factors associated with it in four districts of Bauchi local government, Bauchi State Nigeriausing ELISA kit and a structured questionnaire survey. Blood samples were collected froma total of 270 cattle (56 males and 214 females). The data generated were analysed using SPSS and chi-square test was used for comparison of variables. The result showed that out of the 270 serum samples tested, 171 (63.3\%) were found to be positive for FMDV antibodies.Individual district prevalence rates were Bauchi (79.4\%), Galambi (50\%), Miri (61.1\%) and Zungur (64.3\%). No statistical difference $(P>0.0001)$ was noted in the distribution of the positive samples among the four districts studied. Breeds distribution showed that Muturu had 2/2 (100\%) FMD seropositivity, followed by Sokoto Gudali (Bokoloji) and white Fulani (Bunaji) having 2/3 (66.67\%) and 153/235 (65.11\%) respectively; and the lowest prevalence was among the Cross breed 14/30 (46.67\%). There was no statistical significance $(P>0.0001)$ observed among the different breeds. The seroprevalence of FMD among the different sexes showed the female cattle have 155/214 (72.43\%) as against the male cattle with 16/56 $(28.57 \%)$. There was significant difference $(P \leq 0.0001)$ in the seroprevalence of FMD between the female and male cattle in the study area. There were significant differences $(P \leq 0.0001)$ in the seroprevalence of FMD in the cattle population among the four districts. On the overall, serotype $O$ had the highest prevalence (83.3\%) followed by serotype A (76.7\%) and least was the serotype SAT2 (61.1\%). With the exception of Miri district where serotype SAT2 was higher (66.7\%) than the other two, all the districts exhibited prevalence of the serotypes in descending order of prevalence as Serotype O, A and SAT2. Due to the high prevalence of FMD in the study area, it is therefore important thatsurveillance of FMD should be a continuous process so that an effective control measure against the disease could be taken.
\end{abstract}

Key words; FMD, ELISA, Questionnaire survey, Cattle breeds, Blood

\section{Introduction}

Foot and Mouth Disease (FMD) (also known as hoof-and-mouth disease; aphthous fever; sore fever; infectious aphthous stomatitis; aphthae epizooticae) is a highly contagious viral trans boundary disease of both domestic and wild cloven hoofed animals [1], characterized by the formation of vesicles in the buccal and gastrointestinal tract (rumen) mucosa, skin, especially between and above the claws of the feet, teats and udder, loss of appetite and salivation [2;3].

FMD virus (FMDV) consist of a single-stranded, positive-sense RNA genome of approximately 8,500 bases, belonging to the Family Picornaviridae encoded as a large polyprotein, that is cleaved into the structural proteins and nonstructural proteins [4]. There are 7 (seven) distinct serotypes which include Type A, O, C (European types), South African types (SAT1, SAT2, SAT3) and Asiatic Type. Within the serotypes, many strains can be identified by biochemical and immunological tests [5]. The cumulative incidence of FMD serotypes showed that six of the seven serotypes of FMD (O, A, C, SAT-1, SAT-2, SAT-3) have occurred in Africa, while Asia still contends with four sero-types (O, A, C, Asia-1), South America with only three $(\mathrm{O}, \mathrm{A}, \mathrm{C})$ and periodically there have been incursions of SAT-1 and SAT-2 from Africa into the Middle East [6]. In Nigeria, previous reports confirm endemicity of FMD with serious economic losses due to serotypes A, and SAT 2 [7; 8], serotypes O, SAT1 and SAT2 [9]. SAT1 and SAT 2 serotypes antibodies were also demonstrated [10]. Reviews of FMD reported serotypes A, O, SAT 1 and SAT 2 have been responsible for disease outbreaks in Northern Nigeria as these serotypes have been in circulation in the last 54 years $(1955-2009)[11 ; 12]$. The inaccurate reported endemicity of the disease [7] is associated to none reporting of disease outbreaks [8] due to inefficient disease reporting system in the country [13] and this has made planning for prevention and control of the disease very difficult [10]. Rapid and sensitive method of diagnosis is essential for early detection and effective control. In addition to the classical techniques of viral 
isolation in tissue culture and RT-PCR, antigen detection by enzyme linked immunosorbent assay (ELISA) is now routinely used [14]

\section{Study Area}

\section{Materials And Method}

The study was conducted in four districts (Bauchi, Galambi, Miri and Zungur) that make up Bauchi Local Government Area, Bauchi state, Nigeria (Figure 1). The state is in the northeastern part of Nigeria. Bauchi Local Government Area lies between longitude $10.10^{\circ} \mathrm{N}-10.33^{\circ} \mathrm{N}$ and latitude $9.40^{\circ} \mathrm{E}-10.13^{\circ} \mathrm{E}$. Its altitude is $690.2 \mathrm{~m}$ above sea level; and occupies an estimated land area of $3,687 \mathrm{~km}^{2}$ and has a population of 493,810 at the time of the 2006 census. www.Bauchi/wiki.com. Cattle, sheep, and goats, are the main productive livestock reared in the area, and livestock population is estimated to be 1.8 million cattle, 2.8 million sheep, and 3.4 million goats. (Agricultural and Rural Development Bureau of Bauchi state, 2007 Annual Report).

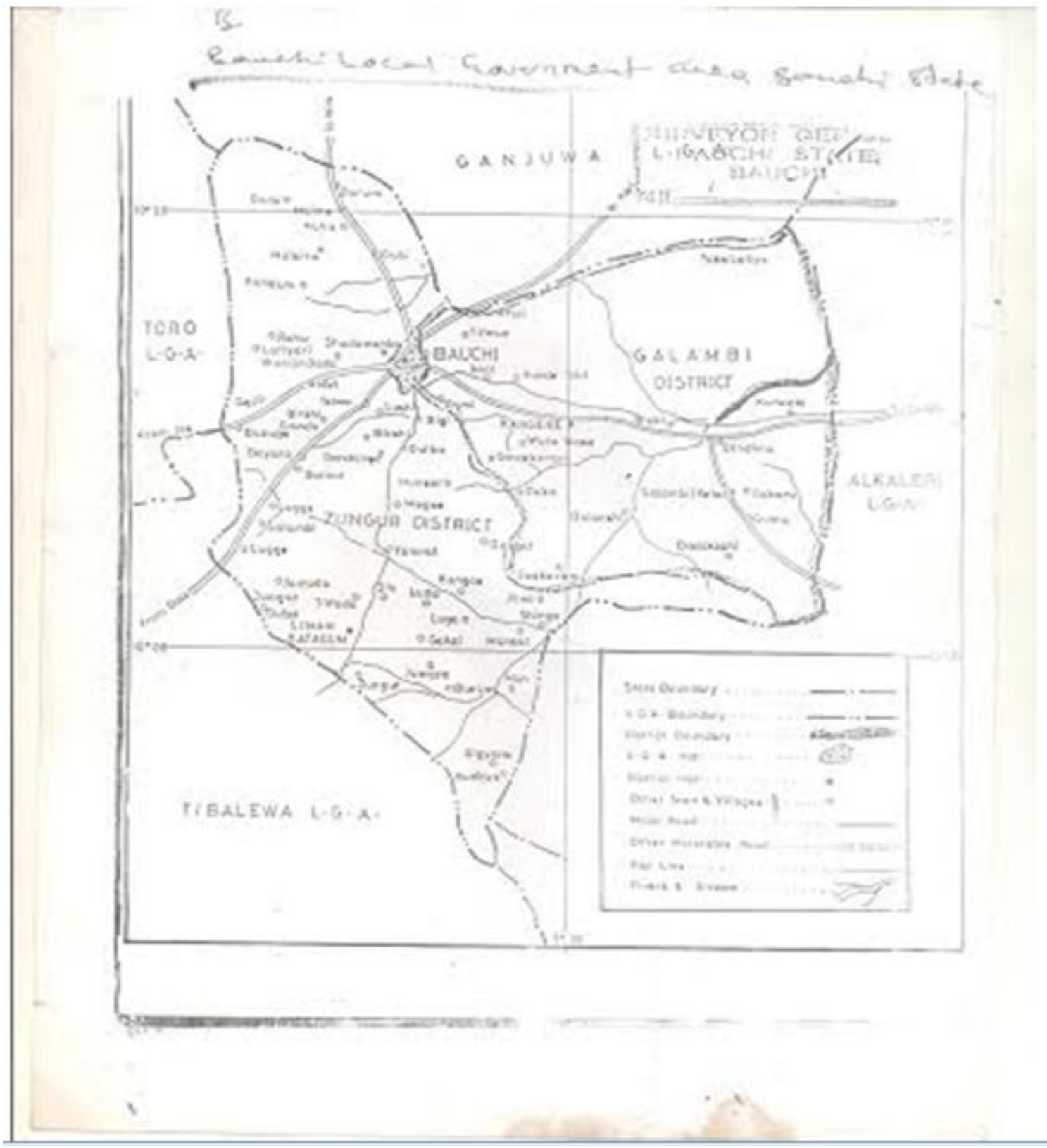

Figure 1. Map of Bauchi LGA Bauchi State Nigeria, showing the study area.

\section{Study design}

Cross sectional study using random sampling was conducted to determine the sero-prevalence of FMD in the cattle population of the four districts in Bauchi State. In addition, questionnaire survey and conventional veterinary investigation methods were applied to generate information on FMD from farmersin the study area. 
Animal health assistants and technicians were also interviewed about the occurrence and outbreak reports of FMD in their respective districts.

\section{Serum Sample Collection and Laboratory Analysis}

A total oftwo hundred and seventy samples (270) were collected by collecting five milliliters (5ml) of whole blood from each cattle through the jugular vein using $5 \mathrm{ml}$ syringe and $22 \mathrm{G}$ needle. The samples were collected into vacutainer tubes and an identification code was given to the sample. Each blood sample was kept in a slanting position to allow for clotting of the blood and transported on ice pack in a cooler to the National Veterinary Research Institute Bauchi Laboratory and kept in a slanting position overnight at room temperature for serum separation. Each serum was transferred into a single sterile well labeled cryotube, bearing the names of the owner and PA, herd number, breed, age and sex. The sera were harvested into cryotubes and kept at $20^{\circ} \mathrm{C}$ until tested. The harvested sera were then transported to the National Veterinary Research Institute, Vom. The harvested sera were analysed for FMD prevalence using The PrioCHECK ${ }^{\circledast}$ FMDV-NS blocking ELISA to identify the serotypes of the disease in the area using manufacturer's protocol.

\section{Data Analyses}

The data generated from the field was entered into a computer on a Microsoft Excel spreadsheet and analyzed using SPSS version 16 software program (2007). Categorical variables (sex, age and sites) were considered. Prevalence was calculated by dividing the number of 3ABC ELISA positive animals by the total number of animals tested. Chi-square test was used for comparison of variables and tests were considered as significant at $\mathrm{P} \leq 0.0001$.

\section{Results}

Out of the 270 serum samples tested, $171(63.3 \%)$ were found to be positive for FMDV antibodies (Table 1). The highest prevalence rate was recorded in Bauchi (79.4\%). This is followed by Zungur, Miri and Galambi with the prevalence rates of $64.3 \%, 61.1 \%$ and $50 \%$ respectively. Although no statistical difference between them.

Table 1: Seroprevalence of FMD among the cattle population of four districts in Bauchi LGA,n Bauchi State,

\begin{tabular}{|l|l|l|}
\hline \multicolumn{2}{|c|}{ Nigeria } \\
\hline District & Total no. tested & No. (\%) Positive \\
\hline Bauchi & 102 & $81(79.4)$ \\
\hline Zungur & 28 & $18(64.3)$ \\
\hline Miri & 18 & $11(61.1)$ \\
\hline Galambi & 122 & $61(50)$ \\
\hline Total & 270 & $171(63.3)$ \\
\hline
\end{tabular}

There is variation in the distribution of FMD among the different breeds of cattle used in this study. Muturu, for instance, showed $100 \%$ seroprevalence, followed by Sokoto gudali (Bokoloji) and white Fulani (Bunaji) having $66.67 \%$ and $65.11 \%$ respectively; and the lowest prevalence was among the Cross breed with 46.67\% prevalence (Table 2). However, no statistical difference in seroprevalence of FMD among these breeds.

Table 2: Breed distribution of FMD seroprevalence among cattle population in four Districts of Bauchi LGA of Bauchi state, Nigeria

\begin{tabular}{|l|l|l|}
\hline Breed & Total no. tested & No. (\%) Positive \\
\hline White Fulani (Bunaji) & 235 & $153(65.11)$ \\
\hline Crossed (White fulani and Friesian) & 30 & $14(46.67)$ \\
\hline Sokoto gudali (Bokoloji) & 3 & $2(66.67)$ \\
\hline Muturu & 2 & $2(100)$ \\
\hline Total & 270 & $171(63.3)$ \\
\hline
\end{tabular}

$\left(\mathrm{X}^{2}=5.079 ; \mathrm{DF}=3, \mathrm{P}=0.1661\right)$

Female cattle showed highest seroprevalence of FMD of $72.43 \%$ against the male cattle that had $28.57 \%$. There is significant difference $(\mathrm{P} \leq 0.0001)$ in the seroprevalence of FMD between the female and male cattle in the study area (Table 3).

Table 3: Sex distribution of FMD seroprevalence among cattle population in four districts of Bauchi LGA of Bauchi State, Nigeria

\begin{tabular}{|l|l|l|}
\hline Sex & Total no. tested & No. (\%) positive \\
\hline Female & 214 & $155(72.43)$ \\
\hline Male & 56 & $16(28.57)$ \\
\hline Total & 270 & $171(63.33)$ \\
\hline
\end{tabular}


$(\mathrm{P}=0.0001 ; \mathrm{RR}=0.3945)$

Based on age distribution, there were statistical differences of FMD seropositivity between different age brackets of cattle in the four districts of this study. Adult greater than three years recorded the highest FMD prevalence of $80.79 \%$ when compared to $50.59 \%$ and 17.65 recorded by young $(1-3$ year) and calf $(<1$ year $)$ respectively (table 4$)$

Table 4: Age distribution of FMD seroprevalence among cattle population in four districts of Bauchi LGA of Bauchi State, Nigeria

\begin{tabular}{|l|l|l|}
\hline Age category & Total no. tested & No. $(\%)$ positive \\
\hline Calf(<1year) & 34 & $6(17.65)$ \\
\hline Young(1-3year) & 85 & $43(50.59)$ \\
\hline Adult(>3year) & 151 & $122(80.79)$ \\
\hline Total & 270 & $171(63.33)$ \\
\hline
\end{tabular}

$\left(\mathrm{X}^{2}=56.331 ; \mathrm{DF}=2, \mathrm{P}=0.0001\right)$

On the overall, serotype $\mathrm{O}$ had the highest prevalence $(83.3 \%)$ followed by serotype A (76.7\%) and least was the serotype SAT2 $(61.1 \%)$ (Table 5). With the exception of Miri district where serotype SAT2 was higher $(66.7 \%)$ than the other two, all the districts exhibited prevalence of the serotypes in descending order of prevalence as Serotype O, A and SAT2.

Table 5: Seroprevalence of FMD serotypes among cattle population in four districts of Bauchi LGA of Bauchi state, Nigeria

\begin{tabular}{|l|l|l|l|l|}
\hline District & Total no. tested & $\begin{array}{l}\text { Serotype O } \\
\text { No. }(\boldsymbol{\%}) \text { positive }\end{array}$ & $\begin{array}{l}\text { Serotype A } \\
\text { No. (\%) positive }\end{array}$ & $\begin{array}{l}\text { Serotype SAT2 } \\
\text { No. }(\%) \text { positive }\end{array}$ \\
\hline Bauchi & $21(100)$ & $20(95.2)$ & $14(66.7)$ \\
\hline Galambi & 21 & $35(77.8)$ & $33(73.3)$ & $29(64.4)$ \\
\hline Miri & 45 & $3(50.0)$ & $2(33.3)$ & $4(66.7)$ \\
\hline Zungur & 6 & $16(88.9)$ & $14(77.8)$ & $8(44.4)$ \\
\hline Total & 18 & $75(83.3)$ & $69(76.7)$ & $55(61.1)$ \\
\hline
\end{tabular}

The result of the questionnaire administered showed that $63.3 \%$ of the farmers interviewed have a knowledge of FMD and described clinical signs they observe for the disease as drooling saliva (80\%), lameness $(51.4 \%)$, wounds on the nares, buccal cavity and coronets $(52.9 \%)$, wounds on the tongue $(68 \%)$, blisters on the udder and teats $(70 \%)$ (data not shown). Eighty two percent $(82 \%)$ of all the respondents indicated to have experienced FMD outbreaks on their farms at least twice $(74.7 \%)$ or once $(54.8 \%)$. Such outbreaks occurs mostly $(80 \%)$ at the end of rainy season and among the adult animals. Sixty three percent $(63.3 \%)$ of the respondents showed that FMD affects the productivity of their animals, and $87.5 \%$ of them do not know of FMD vaccine and $95.8 \%$ have never vaccinated their cattle against FMD (data not shown).

\section{Discussion}

Foot and Mouth Disease is an endemic and one of the most important trans-boundary animal diseases that limits prospects in local livestock production in Nigeria, with outbreaks occurring seasonally [15]. The seroprevalence of $63.3 \%$ obtained from this study could only be from field infection with FMDV because the ELISA kit used in this study detects antibodies directed against the non-structural 3ABC protein of FMDV, confirming FMDV infected animals independent of animal vaccination status. This higher prevalence therefore indicated that FMD is widely distributed among cattle herds in the study area.

The overall seroprevalence obtained in this study is higher than $48.0 \%$ earlier reported by Chukwuedo and Nimzing [16] in Bauchi State. This higher prevalence may be attributed to variation in the serological methods employed in the two different researches. ELISA, which is shown to has high sensitivity and specificity than CFT was used in this study, while the later was used in the study conducted by Chukwuedo and Nimzing [16]. In addition, it is also higher than percentage prevalence reported by Wungak et al. [15](55.9\%) in Plateau State, Nigeria.

Lazarus et al.[17] also reported a lower seroprevalence rate of 27.84\% in Bauchi. However, it is lower than $72.6 \%$ reported by Lazarus et al. [17] from cattle in some boarder states of North West and North Eastern Nigeria.This may be because these towns were the first portal of entry for local cattle from North, East and Central African regions. In this study, significant variation was found in prevalence of FMD between the districts. This probably relates to difference in the existing livestock production system. It was observed in the study that the farmers in Bauchi, Zungur and Miri districts follow the traditional pastoral production system which entails animals traveling long distances and can cross national boundaries, while those in Galambi district 
follow the sedentary system of production. In addition, higher prevalence of the disease in pastoral areas in case of this study could be attributable to possible reasons like unrestricted high herd mobility, continuous contact and intermingling of different herds at water points and communal grazing areas. Ekboir [18] has earlier suggested that movements of infected animals are by far the most important dissemination and transmission means for FMDV. Also Paul et al. [19]) in northern Thailand and Bronsvoort et al. [20] in Cameroon observed the influence of the movement and keeping animals at homestead in the incidence of FMD. Another reason could be attributable to the fact that there has been no record of comprehensive vaccination campaign undertaken in the Bauchi, Zungur and Miri districts, like in Galambi district. Breed variation in the sero-prevalence of FMD between local (White Fulani, Sokoto gudali, Muturu) and cross breeds (White Fulani and Friesian) were found to be statistically non-significant(Table 2).

Sex distribution indicated seropositivity was highest amongst female (cows) $72.43 \%$ than the male (bulls) $28.57 \%$. jThis finding was not consistent with the findings of Jenbere et al. [21] that showed that sex has no difference in risk association with FMD transmission. It also contradicts the findings of Fakai et al. [22] on pigs; Esayas et al. [23] and Megersa et al. [24] in Ethiopia. This variation may be attributed to high number of females sampled at various locations as more cows are seemly found in herds.

The study revealed a significant variation in seropositivity of foot and mouth disease among the three age groups. The significantly higher seroprevalence of FMD in young and adult animals than in calves might be because adults have acquired the infection through repeated exposure to the different serotypes of the virus and could get access to mixing with other herds at watering points and communal grazing areas. Conversely, the calves have low frequency of exposure to the virus and prevailing passive maternal immunity can give them protection against the disease; in addition farmers in the study area keep their calves around the homestead, where there is less contact with other herds. Moreover, other attributes might be that the sample size of the three age groups was not proportional. The increasing seroprevalence of FMD with age disagrees with previous report by Isholo et al. [25] who noted that cattle within the age of 1-2 years are more prone to FMD.

In this study significant difference in FMD seroprevalence was observed between mixed herds $(70.76 \%)$ and cattle only herds $(50.51 \%)$ suggesting the role of other ruminants kept alongside the cattle. This finding was in agreement with a previous study in Bench Maji, Southwestern Ethopia [26]. It is also observed in this study that FMD prevalence tended to increase with herd size. This finding was in agreement with a previous study where herd size was designated as a risk factor in FMDV infection [27]. This could be due to the contagious nature of the disease and mode of transmission which is enhanced by crowding and frequency of contact [28]. Overall, serotype $\mathrm{O}$ was the most prevalent serotype in the four districts of Bauchi L.G.A where it had prevalence rate of 83.33\% followed by serotypes A (76.67\%) and SAT $2(61.11 \%)$. The three serotypes are normally incorporated in the quadrivalent vaccine that is commonly used for control of FMD in West Africa. In Nigeria, as in other parts of Africa, the use of vaccines is sub-optimal in relation to the cattle population of the region [29].

From the questionnaire survey result, $92 \%$ (46/50) of respondents described well most of the local perceptions of the disease signs the indigenous epidemiological knowledge that the FMD occurs usually during the end of rainy season (October-December) when feed is available. The clinical signs listed were consistent with what is indicated in Veterinary literatures [30;31;32]. The information obtained from the community indicated that the incidence of occurrence of FMD increases as age increases. This may indicate the cumulative experience of the population with the agent [33]. The survey also showed that the disease was fatal in young and adult than in calves and seasonal incidence was high during the end of raining months of the year. This seasonal pattern and age as a factor in multivariate analysis was also consistent with the result obtained from this univariate analysis.

\section{Conclusion}

1- A total seroprevalence rate of $63.3 \%$ was found for FMD in this study

2- Bauchi district recorded the highest FMD seroprevalenc rate of $79.4 \%$ and Galambi district recorded the lowest seroprevalence rate of $50 \%$

3- Muturu breed of cattle had 100\% FMD seroprevalence rate while the lowest seroprevalence rate of $46.67 \%$ was recorded in cross breed

4- Female cattle showed highest FMD seroprevalence rate of $72.43 \%$ as against male with $28.57 \%$

5- Adult greater than 3 years recorded the highest FMD seroprevalence of $80.79 \%$ and young calf less than one year recorded the lowest FMD prevalence of $17.65 \%$

6- Serotype O had the highest seroprevalence rate of $83.3 \%$ and least was serotype SAT 2 with $61.1 \%$

7- The result of the questionnaire showed that $63.3 \%$ of the farmers have knowledge of FMD; $82 \%$ have experienced outbreaks of FMD in their farms mostly in the rainy season; $87.5 \%$ do not know of FMD vaccine and $95.8 \%$ have never vaccinated their cattle against FMD 


\section{References}

[1] Di Nardo A, Knowles NJ, Paton DJ. Combining livestock trade patterns with phylogenetics to help understand the spread of foot and mouth disease in sub-Saharan Africa, the Middle East and SoutheastAsia.Review Science Technical Office International Epizootics. 2011; 30 (1): 63-85

[2] Kitching RP. Identification of foot and mouth disease virus carrier and sub-clinically infected animals and differentiation from vaccinated animals. Science and Technology Review. 2002; 21: 531-538

[3] Thomson GR. Foot and mouth disease. In: Infectious diseases of livestock with special reference to Southern Africa, edited by JAW. Coetzer, GR. Thomson. Cape Town, London, New York: Oxford University Press. 1994; 825-992.

[4] Shao J, Hui-yun C, Guang-qing Z, Guo-zheng C, Jun-zheng D, Tong L, et al.,. RT Rapid Detection of Foot-and-Mouth Disease Virus by Reverse Transcription Loop-mediated Isothermal Amplification (RT-LAMP). International Journal of Applied Research in Veterinary Medicine, 2010; 8(2): 133-140.

[5] Office International for Epizootics (OIE). Foot and mouth disease In: OIE Terrestrial Manual of Diagnostic tests and vaccines for terrestrial animals (mammals, birds and bees): $5^{\text {th }}$ edition, volume I. Office international des Epizooties (OIE), Paris, France. 2008; $111-128$.

[6] Rweyemamu M, Roeder P, Mackay D, Sumption K, BrownlieJ, Leforban Y, et al. Epidemiological patterns of foot and mouth disease worldwide. Transboundary and Emerging Disease. 2008; 55, 57-72.

[7] Nawathe DR, Goni M. Foot-and-Mouth Disease in Nigeria. Bulletin of Animal Health and Production in Africa. 1976;24(1): 1-4.

[8] Durojaiye AO, Incidence of Foot and Mouth Disease in Oyo State of Nigeria. Nigerian Veterinary Journal. 1981; 10 : 7-13.

[9] Abegunde AA. Studies on the epidemiology of foot and mouth disease in Nigeria. PhD Thesis. Ahmadu Bello University, Zaria. $1987 ; 124-126$

[10] Chukwuedo AA, Nimzing L, Olabode AO, Abegunde A. Prevalence of Foot and Mouth disease Virus, SAT 1 and SAT 2 serotype antibodies in Nigerian cattle. Animal Production Research Advances. 2008;4 (2):157-160.

[11] Nwanta JA, Ojemiren FO. Epidemiology of Foot and Mouth Disease (FMD) in northern states of Nigeria. Up-date In: Proceedings of the $36^{\text {th }}$ Annual Congress of the National Veterinary Medical Association held in Kaduna, $25^{\text {th }}-29^{\text {th }}$ October 1999; $11-18$.

[12] Olabode HOK. Foot and Mouth disease in Nigeria: The current status and control efforts. A Paper presented at the Global Foot and Mouth Disease Research Alliance workshop organized by ARC-Onderstepoort Veterinary Institute, held at Hazy-view, Kurger National Park, South Africa on the $17^{\text {th }}-19^{\text {th }}$ April, 2012. 2012; Availableat:

http://www.ars.usda.gov/GFRA/presentations/Session3/3.4OlabodeFMD\%20POWERPOINT.pdf

[13] Chukwuedo AA, Abegunde A, Gomwalk NE.Studies on current status of foot and mouth disease virus in Nigeria. Nigerian Journal of Biotechnology. 2003; 14 (1):22-28.

[14] Kitching RP. Foot and Mouth disease. In: Bovine medicine: Diseases and husbandry of cattle (A. H. Andrews, R. W. Blowey, H. Boyd, and R.G. Eddy, eds). Oxford, Blackwell science Inc. Malden and oxford. 1992; 537-543.

[15] Wungak YS, Lazarus DD, Agom D, Ularamu HG. Serological evidence of foot and mouth disease virus (FMDV) antibodies in pigs from north eastern Nigeria. Journal of Veterinary Medicine and Animal Health. 2015; 7(7); 257-260

[16] Chukwuedo AA, Nimzing L. Field investigation of foot and mouth disease virus infection in cattle in northern States of Nigeria.Nigerian Journal of Biotechnology.2012; 24; 20-26.

[17] Lazarus DD, Schielen WJG, Wungak Y, Kwange D, Fasina FO. Sero-epidemiology of foot-and-mouth disease in some Border States of Nigeria.Africa Journal of Microbiology Research. 2012; 6(8): 1756-1761

[18] Ekboir JM. Potential impact of foot and mouth disease in California; The contribution of animal health surveillance and monitoring services. University of California Agricultural Issues Center. 1999; 7-13.

[19] Paul C, Cleanda F, Chris B, Pornchai C, Laurence JG. Village level Risk factors for foot and mouth disease in Northern Thiland. Preventive Veterinary Medicine. 1996; 26: 253- 261.

[20] [20] Bronsvoort BM, Nfon C, Hamman SM, Tanya VN, Kitching RP, Morgan KL. Risk factors for herdsman-reported foot and mouth disease in the Adamawa province of Cameroon. Preventive Veterinary Medicine. 2004; 66: 127-39

[21] Jenbere TS, Etana M, Negussie H. Study on the risk factors of Foot-and-Mouth disease in selected Districts of Afar Pastoralist Area, North-Eastern Ethiopia. Journal of Animal and Veterinary Advances. 2011; 10: 1368-1372.

[22] Fakai LU, Faleke OO, Magaji AA, Ibitoye EB Alkali BR. Seroprevalence of foot and mouth disease virus infection in pigs from Zuru, Nigeria. Veterinary World, 2015; 8(7):865-869

[23] Esayas G, Gelagay A, Tsegalem A, Kassahun A. Seroprevalence of foot and mouth disease in Bench Maji zone, southwestern Ethiopia. Journal of Veterinary Medicine and Animal Health. 2009;1:5-10.

[24] Megersa B, Beyene B, Abunna F, Regassa A, Amenu K, Rufael T. Risk factors for foot and mouth disease seroprevalence in indigenous cattle in Southern Ethiopia:The effect of production system. Tropical Animal Health and Production. 2009;41:891-898.

[25] Ishola OO, Wungak YS., Olugasa BO, David LD, Ekong PS. Serological survey of Foot and Mouth disease in cattle in Jos south local government area of Plateau State. Vom Journal of Veterinary Sciences.2011; 8: 16-21

[26] Gelaye E, Ayelet G, Abera T, Asmare K. Seroprevalence of foot and mouth disease in Bench Maji zone, Southwestern Ethiopia Journal of Veterinary Medicine and Animal Health.2009; 1(1):005-010

[27] Hugh-Jones ME. Epidemiological studies on the 1967-68 Foot and Mouth Disease epidemic: attack rates and cattle density. Research inVeterinary Science. 1972; 13(5): 411-417.

[28] Ruffael T, Participatory appraisal and seroepidemological study of Foot and Mouth Disease in Borena Pastoral areas. 2006; FVM, AAU, MSc Thesis, Unpublished.

[29] [29] FAO., 2005-2006. Empres Watch. FMD Foot-and-Mouth Disease. Situation Worldwide and Major Epidemiological Events, Retrived from: http: // www.fao.org/docs/eims/upload/225050/Focus-ON-1-07-en.pdf

[30] Catley OS, Okoth J, Osman T, Fison Z, Njiru J, Muwangi BA, et al. Participatory Diagnosis of chronic wasting disease in cattle in southern Sudan.PreventiveVeterinaryMedicine. 2001; 51:161-181

[31] Catley A,RT. Chibunda,E, Ranga S, Makunga FT, Magayan G, Magoma MJ, et al.Participatory Diagnosis of heat intolerance syndrome in cattle in Tanzania and association with Foot and Mouth Disease. Preventive Veterinary Medicine. 2004; 5:1730.

[32] Radostits OM, Blood DC, Gay CC. Veterinary Medicine, $8^{\text {th }}$ edition. London: Bailliere Tindall. 1994; $345-372$.

[33] Murphy FA, Gibbs EPJ, Horzinek MC, Studdert MJ. Veterinary Virology, $3^{\text {rd }}$ edition. USA, Academic press. $1999 ; 412-421$. 